\title{
ALINHAMENTO ENTRE MODELOS DE GESTÃO DE PESSOAS E OS NÍVEIS DE SUSTENTABILIDADE ORGANIZACIONAL
}

\author{
Alignment between people management models and organizational \\ sustainability levels
}

Terezinha Bernadete Pinto Oliari

E-mail: tbpoliari@gmail.com

Mestre em Administração pela Universidade Estadual do Centro-Oeste; Especialista em Gestão

Estratégica de Organizações pela Universidade Estadual do Centro-Oeste; Professora na

Universidade Estadual do Centro-Oeste. http://orcid.org/0000-0001-7405-8270

Silvio Roberto Stefano

E-mail: professor-silvio@hotmail.com

Pós-doutor em Administração pela Universidade do Vale do Itajaí; pós-doutorando em Gestão pela Universidade do Porto; Professor no Mestrado Profissional em Administração e no Mestrado e Doutorado Interdisciplinar em Desenvolvimento Comunitário da Universidade Estadual do Centro-Oeste. Endereço para contato: Rua Salvatore Renna, 875, 85015-430, Santa Cruz, Guarapuava, Paraná, Brasil. https://orcid.org/0000-0002-5871-8686

Sandra Mara de Andrade E-mail: prof.sandraandrade@hotmail.com

Doutora e Mestre em Administração pela Universidade de São Paulo; Professora no Departamento de Administração e no Mestrado profissional da Universidade Estadual do Centro-Oeste. https://orcid.org/0000-0003-1671-3761

Artigo recebido em 21 de fevereiro de 2020. Aceito em 28 de outubro de 2020. 


\section{Resumo}

A discussão das questões da sustentabilidade vem ganhando corpo nas organizações com a busca do desenvolvimento sustentável organizacional e com o consumo de produtos ecológicos, fazendo com que as indústrias implementem suas atividades e seus processos produtivos com políticas e práticas de gestão mais eficazes e eficientes. Essas exigências de mercado, atualmente, vêm mudando o conceito e as estratégias sustentáveis que a organização desenvolve; nesse contexto, a gestão de pessoas tem papel crucial nas ações, uma vez que a gestão das políticas e práticas planejadas e executadas pela gestão de pessoas tende a auxiliar na posição desejável no nível de sustentabilidade organizacional. Assim, o tema estudado merece uma reflexão mais aprofundada na academia e nas organizações. Este estudo buscou compreender de que forma acontece o alinhamento dos modelos estratégico e sustentável da gestão de pessoas e os níveis de sustentabilidade organizacional de duas indústrias de papel e celulose. Para isso, realizou-se um estudo de casos múltiplos nessas duas indústrias, as quais se configuram como empresas que estão em reestruturação das estratégias visando à implementação da sustentabilidade para o melhor desempenho organizacional. Para se alcançar o objetivo geral, foi necessário realizar uma ampla pesquisa bibliográfica, com entrevistas semiestruturadas com diretores e funcionários - estratégicos e táticos -, além de observação assistemática e análise dos documentos das empresas nos sites. Por meio da análise do conteúdo foi possível verificar que os níveis de sustentabilidade das indústrias estão relacionados ao modelo de gestão de pessoas adotado para o gerir das empresas.

Palavras-chave: Políticas e práticas de gestão de pessoas. Triple Bottom Line (TBL). Indústria de papel e celulose. Modelos de gestão de pessoas.

\section{Abstract}

The discussion of sustainability issues is taking shape in organizations with the search for sustainable organizational development; with the consumption of ecological products, making the industries implement their activities and their production processes with more effective and efficient management policies and practices. These market demands are currently changing the concept and sustainable strategies that the organization develops; in this context, people management plays a crucial role in actions, since it is the management of policies and practices planned and implemented by people management tend to help in the desirable position in the level of organizational sustainability. The theme studied deserves further reflection in academia and organizations. This paper seeks to understand how the strategic and sustainable models of people management are aligned and the levels of organizational sustainability of two pulp and paper industries. This purpose, a multiple case study was carried out in these two industries, which are configured in companies that are restructuring strategies aimed at implementing sustainability for the best organizational performance. In order to achieve the general objective, it was necessary to conduct a wide bibliographic search, with semi-structured interviews with directors and employees - strategic and tactical -, in addition to unsystematic observation and analysis of the companies' documents on the websites. Through content analysis, it was possible to verify that the levels of sustainability of industries are related to the people management model adopted to manage companies. Keywords: People management policies and practices. Triple Bottom Line (TBL). Pulp and paper industry. People management models. 


\section{INTRODUÇÃO}

A sustentabilidade assumiu, nos últimos vinte anos, um papel central nas organizações, com reflexões voltadas às dimensões econômica, ambiental e social. Esse quadro engloba a preservação do ecossistema com a produção de produtos ecologicamente corretos, atentando para as necessidades dos colaboradores por meio de políticas e práticas que visem ao bemestar, à qualidade de vida, à segurança e ao desenvolvimento do indivíduo, assim como ao aspecto social (Elkington \& Zeitz, 2014; Savitz \& Weber, 2013).

Nesse sentido, Galleli e Hourneaux (2019) apontam que as organizações que utilizam a gestão para comunicar e disseminar as implementações de sustentabilidade podem ter maior rentabilidade com a estratégia da sustentabilidade.

Surge, assim, a necessidade de adaptação e mudanças nas organizações e na maneira de gestão, mudanças essas relacionadas à forma dos gestores de orientar e promover a sustentabilidade por meio do comportamento sustentável e das estratégias sustentáveis; essas mudanças, no entanto, tendem a ser mais no modelo comportamental do que nas políticas e práticas sustentáveis, principalmente na gestão de pessoas.

Para diversos autores, como Savitz e Weber (2013), Oliveira (2008), Veiga (2010) e Galleli e Hourneaux (2019), a gestão de pessoas tem muito a contribuir com o desempenho organizacional, pois tem o poder de implementar a sustentabilidade por meio da comunicação interna, uma vez que são grandes disseminadores de ideias e ações coerentes aos objetivos traçados nas estratégias. Cabe ressaltar, porém, que essas ações devem ser planejadas em alinhamento com a alta diretoria, com estrategistas e com a gestão de pessoas.

Dessa forma, a organização que visa ao desenvolvimento sustentável estará integrada na disseminação da sustentabilidade em todos os níveis operacionais, a saber, estratégico, tático e operacional. Outro fator fundamental é a seleção de talentos voltados aos objetivos traçados. No entanto, Galleli e Hourneaux (2019) salientam que não existe um modelo pronto para moldar uma organização, mas a adaptação dos modelos de gestão sustentáveis, fazendo com que as ferramentas de gestão da sustentabilidade se moldem às necessidades da organização, interagindo para diminuir os riscos de mercado e aumentar o desempenho organizacional.

Partindo do pressuposto de que a valorização da sustentabilidade em todos os níveis operacionais tem um melhor posicionamento das diretrizes do que as políticas e práticas de gestão de pessoas assumem nas empresas, fica evidente que o gestor de gestão de pessoas deve ter uma visão ampliada da sustentabilidade (Ulrich, 2000; Savitz \& Weber, 2013).

Visando contribuir com as mudanças organizacionais, Van Marrewijk e Werre (2003) expõem que cada organização deve fazer sua escolha com relação ao nível de sustentabilidade que deseja combinar com os objetivos estratégicos em consonância com o ambiente no 
qual opera, com conjuntos diferenciados que impliquem transparência, divulgação pública e engajamento de todos os envolvidos interna e externamente à organização.

A partir dessa visão, os autores Van Marrewijk e Werre (2003) apresentam os seis níveis de sustentabilidade que podem ser controlados pelas empresas, dependendo das escolhas estrategicamente planejadas pela alta direção, fazendo grande diferença. Segundo Gonçalves et al. (2017), as questões e ações de sustentabilidade organizacional são decididas e implementadas por meio de suas lideranças.

Nesse contexto, Sroufe et al. (2010) entendem como um novo paradigma a abordagem da gestão de pessoas, que vem colaborar com as políticas e práticas de sustentabilidade por meio de seleção, treinamentos, cargos e salários e, principalmente, comunicando e divulgando as estratégias voltadas à sustentabilidade. Assim, este trabalho tem como objetivo principal compreender de que forma acontece o alinhamento dos modelos estratégico e sustentável da gestão de pessoas e os níveis de sustentabilidade organizacional de duas indústrias de papel e celulose. Uma pesquisa qualitativa, com estudo de casos múltiplos em duas indústrias, as quais são empresas de destaque em suas atividades e que têm papel fundamental na sociedade na qual estão inseridas por suas práticas e ações voltadas à sustentabilidade.

Desenvolveu-se o estudo da literatura que integra as duas frentes teóricas: sustentabilidade organizacional e modelos de pessoas. Para uma investigação empírica, as empresas Mata Atlântica Cia e Amazônia Cia (nomes fictícios, para resguardar a identidade das empresas), foram as indústrias de papel e celulose foco deste estudo. A coleta de dados envolveu observação assistemática, entrevistas com roteiro semiestruturado e análise documental on-line nos sites das empresas e em documentos disponibilizados por elas, os quais permitiram o levantamento de informações que foram examinadas por meio de análise de conteúdo. A seguir apresenta-se o referencial teórico do estudo.

\section{FUNDAMENTAÇÃO TEÓRICA}

\subsection{MODELOS DE GESTÃO DE PESSOAS}

Uddin e Hossain (2015) descrevem os modelos de gestão de pessoas como o modo como os gestores conduzem uma organização por meio de seus integrantes internos, sendo relevante em sua concepção, uma vez que define a cultura e a filosofia das organizações, incrustadas na empresa por meio de seus fundadores. Essa filosofia, na grande maioria das vezes, é o "coração" que impulsiona a organização.

Com um breve reconstituir dos modelos de gestão de pessoas é possível ver que atualmente os modelos de gestão evoluíram, estando preservada, contudo, a essência 
do primeiro modelo de gestão de pessoas no modelo mais recente. Por meio de estudo bibliográfico minucioso acerca de autores nacionais e internacionais como Albuquerque et al. (2009), Araújo (2006), Badawy (1988), França (2015), Marras e Tose (2013), Orlickas (2012), Trompenaars e Coebergh (2014) e Vosburgh (2007), foi possível reunir uma perspectiva histórica das teorias e abordagens da Administração, com ênfase na Gestão de Recursos Humanos e Gestão de Pessoas, conforme Tabela 1.

Tabela 1

Modelo de Gestão de Pessoas e suas Características

\begin{tabular}{|c|c|c|c|}
\hline $\begin{array}{c}\text { Modelo de Gestão } \\
\text { de Pessoas/Forma de } \\
\text { Gerenciamento }\end{array}$ & $\begin{array}{l}\text { Condições socioeconô- } \\
\text { micas }\end{array}$ & Principais Precursores & $\begin{array}{c}\text { Escolas e Teorias/Modelo de } \\
\text { Gestão Organizacional }\end{array}$ \\
\hline $\begin{array}{l}\text { Modelo de Gestão de } \\
\text { Pessoas como Relações } \\
\text { Industriais } \\
\text { Engenheiro } \\
\text { Chefe de Indústria }\end{array}$ & $\begin{array}{l}\text { Os grandes Gênios em- } \\
\text { presariais. } \\
\text { Modelo voltado à "produ- } \\
\text { ção industrial". } \\
\text { Não existia RH. } \\
\text { Modelo de produção em } \\
\text { massa. }\end{array}$ & $\begin{array}{l}\text { John Davison Rocke- } \\
\text { feller; } \\
\text { J.P. Morgan; } \\
\text { Andrew Carnegie; } \\
\text { Henry Ford; } \\
\text { Meyer Guggenheim; } \\
\text { Afred Sloan. }\end{array}$ & $\begin{array}{l}1850 \text { a } 1940 \text { - (Século XVIII). } \\
\text { Início das Escolas de Negó- } \\
\text { cios. } \\
\text { Gestão Industrial }\end{array}$ \\
\hline $\begin{array}{l}\text { Modelo de Gestão } \\
\text { como Departamento de } \\
\text { Pessoal } \\
\text { Chefe de Pessoal }\end{array}$ & $\begin{array}{l}\text { Medição nos resultados } \\
\text { por intermédio da "gestão } \\
\text { científica". } \\
\text { Direitos dos trabalha- } \\
\text { dores com processos } \\
\text { formalizados } \\
\text { Especialistas com maior } \\
\text { eficiência } \\
\text { Início de RH no Brasil }\end{array}$ & $\begin{array}{l}\text { Frederick Winslow } \\
\text { Taylor. }\end{array}$ & $\begin{array}{l}1900 \text { a } 1930 \text { - (Século XIX). } \\
\text { Teoria da administração } \\
\text { Científica. } \\
\text { Escola Harvard Business. } \\
\text { Teoria das Relações Huma- } \\
\text { nas e Administração. } \\
\text { Científica. } \\
\text { Administração de Pessoal da } \\
\text { Segunda Guerra Mundial. } \\
\text { Fase Contábil. } \\
\text { Gestão de Negócio. }\end{array}$ \\
\hline $\begin{array}{l}\text { Modelo Gestão do } \\
\text { Comportamento Hu- } \\
\text { mano } \\
\text { Gerente de Pessoal }\end{array}$ & $\begin{array}{l}\text { Reconhecendo o poten- } \\
\text { cial humano } \\
\text { "relações humanas". }\end{array}$ & $\begin{array}{l}\text { Elton George Mayo; } \\
\text { Alfred D. Chandler; } \\
\text { Kenneth Andrews Rich- } \\
\text { mond; } \\
\text { lgor Ansoff; } \\
\text { Michael Porter. }\end{array}$ & $\begin{array}{l}1927 \text { a } 1932 \text { - } \\
\text { (Década de 1920). } \\
\text { Teoria de Recursos Humanos } \\
\text { Fase Legal } \\
\text { Gestão Administração Cien- } \\
\text { tífica }\end{array}$ \\
\hline
\end{tabular}

Início da interdisciplinaridade.

Modelo de Gestão como Administração de Recursos Humanos Gerente Industrial

Modelo da Administração de Pessoas Administradores
O conceito de gerenciamento de RH torna-se mais organizado. $O$ conceito de gerenciamento de RH torna-se mais organizado.

Criação das áreas de administração.

Era administrativa ou sindicalista. Marco entre a relação Capital e trabalho. Implantação dos sindicatos
1950 a 1965 -

(Década de 1950).

Max Weber. Teoria Estruturalista.

Fase Tecnicista.

Gestão Administrativa.
1965 a 1970 -

(Década de 1960).

Lyndall Urwick. Teoria de Sistemas.

Fase da Administração.

Gestão Administrativa. 


\begin{tabular}{|c|c|c|c|}
\hline $\begin{array}{c}\text { Modelo de Gestão } \\
\text { de Pessoas/Forma de } \\
\text { Gerenciamento }\end{array}$ & $\begin{array}{l}\text { Condições socioeconô- } \\
\text { micas }\end{array}$ & Principais Precursores & $\begin{array}{c}\text { Escolas e Teorias/Modelo de } \\
\text { Gestão Organizacional }\end{array}$ \\
\hline $\begin{array}{l}\text { Modelo Estratégico da } \\
\text { Gestão de Pessoas } \\
\text { Gestor de pessoas }\end{array}$ & $\begin{array}{l}\text { Introdução da ferramenta } \\
\text { Balanced Scorecard. } \\
\text { A estratégia já faz parte } \\
\text { da organização } \\
\text { "Arte da guerra". } \\
\text { "Polícia política". }\end{array}$ & $\begin{array}{l}\text { Elton George Mayo; } \\
\text { Alfred D. Chandler; } \\
\text { Kenneth Andrews Rich- } \\
\text { mond; } \\
\text { lgor Ansoff; } \\
\text { Michael Porter. }\end{array}$ & $\begin{array}{l}\text { Teoria da Contingência. } \\
\text { Gestão Estratégica. }\end{array}$ \\
\hline $\begin{array}{l}\text { Modelo de Gestão de } \\
\text { Pessoas Articulado por } \\
\text { Competências } \\
\text { Gestor de Talentos }\end{array}$ & $\begin{array}{l}\text { Os primeiros acordes do } \\
5 \mathrm{~S} \text { da qualidade }\end{array}$ & $\begin{array}{l}\text { William Edwards Dem- } \\
\text { ing. }\end{array}$ & $\begin{array}{l}1980 \text { a } 1990- \\
\text { (Década de 1980). } \\
\text { Teoria da Qualidade Total. } \\
\text { Gestão da Qualidade. }\end{array}$ \\
\hline $\begin{array}{l}\text { Modelo de Gestão de } \\
\text { Pessoas Sustentável } \\
\text { Gerente de DHO }\end{array}$ & $\begin{array}{l}\text { 3Ps: People, Planet, Profit } \\
\text { Desenvolvimento Susten- } \\
\text { tável e a Sustentabili- } \\
\text { dade organizacional e o } \\
\text { TBL - econômico, social e } \\
\text { ambiental. }\end{array}$ & $\begin{array}{l}\text { John Elkington; } \\
\text { lgnacy Sachs; } \\
\text { Andrew Savitz; } \\
\text { Karl Weber; } \\
\text { Luciano Munck. }\end{array}$ & $\begin{array}{l}1990 \text { a } 2019 \text { - Século XX. } \\
\text { Teoria da Sustentabilidade } \\
\text { Gestão do Desenvolvimento } \\
\text { Sustentável }\end{array}$ \\
\hline
\end{tabular}

A Tabela 1 identifica a evolução contínua dos modelos de gestão de pessoas. Oliari (2019) fez um levantamento da evolução contínua dos principais Modelos de Gestão de Pessoas, que teve início no modelo de gestão de pessoas como relações industriais, com foco na relação industrial, sendo o primeiro modelo identificado, o qual tinha relação direta com o departamento de pessoas, relativizando os funcionários como máquinas produtoras, com um custo elevado para a produção (Trompenaars \& Coebergh, 2014). Contudo, novos conceitos e direcionamentos foram necessários, sendo a formação profissional umas das primeiras, com as formações em direito, medicina e administração na Escola de Harvard, fundada em 1928; com o modelo de Gestão de negócios surge, então, a função de administrador. $O$ segundo Modelo de Gestão como Departamento de Pessoal compreendeu a gestão científica, com movimentos das escolas clássicas e enfoque na administração científica, apresentando os primeiros vestígios da Gestão de Pessoas, ainda que com padrão extremamente burocrático e com a busca de administrar as pessoas, que ainda eram entendidas como custos ao processo produtivo (Orlickas, 2012).

No próximo modelo, o Modelo de Gestão do Comportamento Humano, a preocupação principal era com os procedimentos dos processos e a eficiência nos custos, com a integração entre custos e pessoas. Esse modelo marcou o início da integração entre a administração e a psicologia, visto que o investimento em recursos humanos traria lucro e benefício para a organização. Com esse modelo tem-se maior controle das pessoas em uma relação entre "homens-máquina", denominando-se departamento de Recursos Humanos (Drucker, 2012). Também nesse modelo pode-se citar a introdução das primeiras leis trabalhistas e sindicatos; surgia, assim, o Departamento de Recursos Humanos, com as gerências operacional e tática. 
No entanto, era necessária uma reorganização nos modelos, e então surgiu o Modelo de Gestão Pessoas como Administração de Recursos Humanos. Segundo Marras (2017) e Marras e Tose (2013), esse modelo está ligado à escola de relações humanas, tendo um significado diferente dos primeiros modelos, visto que dá maior ênfase às questões de cargos e salários, assim como aos testes psicológicos e à avaliação do desempenho; foi a evolução das teorias humanistas, com a consolidação das leis trabalhistas (CLT) e os direitos trabalhistas (Marras).

Em 1965, segundo Vosburgh (2007), surgiu o Modelo de Administração de Pessoas, trazendo questões entre as empresas e os sindicatos, como ampliar o respeito pelos funcionários e o lucro, porém com uma visão focada no bem bem-estar dos funcionários, um ponto relevante na administração da organização, no sentido de evitar os problemas de produção; assim, o papel principal do administrador era resguardar a organização de problemas trabalhistas. Porém, esse modelo foi superado pelo Modelo Estratégico da Gestão de Pessoas, e uma nova modelagem surgiu com o planejamento estratégico, centrado na escola de administração, com o tema das práticas estratégicas e o relacionamento entre o sistema das políticas organizacionais e os fatores ambientais, que trazem uma ruptura no modelo genérico das escolas comportamentais, e, assim, surgiram os valores do alinhamento dos fatores internos e externos ao ambiente organizacional. Segundo Fleury e Fischer (2002), uma visão sistêmica em longo prazo envolve os valores e a visão da empresa, principalmente a vinculação das políticas de gestão de pessoas às estratégias organizacionais, além de influenciar diretamente as ações dos atores principais da gestão de pessoas (Galpin, Whittington e Bell, 2015; Gonçalves et al., 2017).

O Modelo de Gestão de Pessoas Articulado por Competências surge com a articulação da performance dos produtos de alta qualidade oriundos do made in Japan, com orientação ao cliente; no foco da gestão da qualidade e das relações humanas, sendo que o conhecimento faz parte integrada das organizações com as competências e a tecnologia internacional (Fischer, 2002).

Porém, uma onda da sustentabilidade, com seus pilares, sugeridos por Elkington (1999), surge na década de 1970, é a visão dos problemas ambientais sendo colocada para os líderes mundiais, com a principal visão da manutenção do ecossistema no mercado mundial, mostrando a necessidade de se desenvolver o meio organizacional e ao mesmo tempo dar continuidade ao ciclo da vida na terra para novas gerações (Elkington \& Zeitz, 2014). Esse modelo pode ser considerado como Modelo de Gestão de Pessoas Sustentável, o qual ainda não foi abordado na literatura como "Modelo de Gestão de Pessoas". No entanto, evidenciaram-se os estudos, principalmente, de três pesquisadores: Galbreath (2010) e Galpin e Hebard (2015), que citam a proposição do modelo quando se estabelece a ligação entre os objetivos estratégicos da organização e as práticas que guiam a sustentabilidade organizacional, e Savitz e Weber (2013), que apontam como fundamental as mudanças estratégias da organização serem integradas à rotina com a gestão de pessoas, assim como 
por meio da sua integração nas rotinas das operações se tem um modelo de gestão de pessoas sustentável. No entanto, Munck (2015) ressalta a importância de a sustentabilidade ser uma proposta de novos modelos de gestão de pessoas. Diante do exposto, utilizou-se como proposta de modelo o Modelo de Gestão de Pessoas Sustentável.

Nessa visão, e diante da necessidade de as organizações procurarem formas inovadoras de administrar a gestão dos profissionais em um mundo globalizado e competitivo, procurase a inserção da sustentabilidade no meio organizacional, sendo este o próximo item a ser melhor explanado.

\subsection{SUSTENTABILIDADE E OS NÍVEIS DE SUSTENTABILIDADE ORGANIZACIONAL}

O marco inicial da sustentabilidade foi em 1987, com o Relatório de Brundtland, o qual trouxe um novo conceito utilizado para o desenvolvimento sustentável, também chamado de "O Nosso Futuro Comum" (Organização das Nações Unidas [ONU], 2015). Esse relatório, de comprometimento da ONU, consagrou o compromisso da proteção da vida na terra por meio da preservação das espécies para as próximas gerações ou, ainda, como consta no relatório, o desenvolvimento sustentável "capaz de permitir a satisfação das necessidades da geração presente sem comprometer a satisfação das necessidades e a sobrevivência das gerações futuras" (Brundtland, 1987, p. 27).

O conceito de sustentabilidade, segundo Elkington (2001), é a atualização dos recursos naturais de maneira racional e equilibrada no cerne de três pilares, o econômico, o ambiental e o social, ou seja, a equidade entre Pessoas (People), Planeta (Planet) e lucro (Profit); nessa perspectiva, o autor propõe o crescimento econômico, porém de maneira consciente a respeito da necessidade do desenvolvimento social e a preservação ambiental, o que é um consenso entre os estudiosos do conceito Triple Bottom Line (TBL) e os orientadores da gestão organizacional sustentável (Pires \& Fisher, 2014).

A sustentabilidade organizacional significa o repensar na gestão, com uma estrutura que seja viável economicamente para todos os stakeholders (acionistas, clientes internos e externos, fornecedores e parceiros), estimulada pela tecnologia e a inovação, que além de trazer ganhos competitivos, mantenha o meio ambiente respaldado da extinção; esse é um dos grandes objetivos da gestão da sustentabilidade nas organizações (Savitz \& Weber, 2013), podendo-se até dizer que é uma gestão visando à lucratividade socioambiental e economicamente correta.

Os autores Elkington e Zeitz (2014), Munck et al. (2016), Borim-de-Souza e Segatto (2015) concordam entre si que os três vértices é que mantêm um desenvolvimento organizacional sustentável. Esse equilíbrio deve existir nas metas e estratégias, visando aos 
pilares social, ambiental e econômico para que haja equilíbrio no TBL e a empresa aumente sua rentabilidade. Esses três pilares isolados podem ser gerenciáveis, no entanto, quando se buscam resultados individuais, as consequências são muitos desafios e tensões para as organizações (Henry et al., 2019).

O sistema dos pilares da sustentabilidade integrada pode resultar em maior desempenho para a empresa, assim como maior lucratividade, no entanto de maneira socialmente justa, ambientalmente correta e economicamente viável, slogan já citado por muitos defensores do TBL, como Savitz e Weber (2013) e Elkington e Zeitz (2014). Cabe salientar que os autores complementam que é a gestão de pessoas que contribui em grande parte para o desempenho contínuo e superior da sustentabilidade organizacional, uma vez que pode evolver equipes, contratar talentos com habilidades voltadas para a sustentabilidade e ser um dos principais comunicadores e multiplicadores da sustentabilidade (Parente \& Fischer, 2015).

Nesse sentido, Van Marrewijk e Werre (2003) apresentaram ao meio acadêmico uma maneira de identificar o quão "madura" está a sustentabilidade em uma empresa, sendo chamada de os níveis de sustentabilidade organizacional, que são buscados por meio de políticas e práticas na gestão de pessoas.

No entanto, ressalta-se que essa gestão é guiada pela escolha do modelo de gestão de pessoas, ou seja, os níveis de sustentabilidade existentes nas organizações têm muito da influência do modelo da gestão de pessoas. A codificação das cores e dos valores do sistema foi iniciada por Beck e Cowan (1996), os quais classificaram os níveis com cores da pesquisa realizada pelo professor Clare W. Graves nos anos 1950 a 1960, a qual foi um estudo empírico sobre a existência dos sistemas de valores comportamentais nos indivíduos de forma individual das pessoas e na forma coletiva, tanto na sociedade quanto nas organizações. Esses valores se inter-relacionam com maior ou menor intensidade; no entanto, esse sistema considera os mesmos valores quando abordado a respeito do meio ambiente, como no comportamento, nos valores, nas crenças e na cultura (Van Marrewijk \& Werre, 2003).

A relação das cores com o sistema de valores ocorreu em ordem fixa no trabalho de Beck e Cowan (1996): Sobrevivência; Segurança; Energia \& Poder; Ordem; Sucesso; Comunidade; Sinergia; e Sistema de vida holística. O sistema desenvolveu-se em reação aos desafios e ameaças ambientais; cada novo sistema de valores incluía e transcendia os anteriores, formando, assim, uma hierarquia natural; nos sistemas das cores a codificação iluminava ou escurecia. Assim como as condições de vida, tempos históricos, lugar geográfico, problemas e circunstância sociais também mudam, o mesmo vem a acontecer com as organizações.

Van Marrewijk e Werre (2003) utilizaram os mesmos princípios para formatar a codificação dos sistemas de valores corporativos, dentre eles missão, visão, implantação de políticas, tomada de decisões, relatórios, assuntos corporativos, estratégias em alinhamento 
aos valores voltados à sustentabilidade corporativa, buscando respostas adequadas para a provável postura que cada corporação tem nas variáveis; no entanto, esses autores utilizaram seis cores para demonstrar o sistema de valores da sustentabilidade, sendo os mesmos códigos de cores introduzidos por Beck e Cowan (1996), respectivamente, vermelho, azul, laranja, verde, amarelo e turquesa.

Cabe salientar que os autores supracitados formularam a matriz dos níveis da sustentabilidade apresentando um novo integrante ao conceito triplo-P, de Profit-PeoplePlanet: o P das Práticas contínuas que, seguindo a teoria da estratégia como prática, pode ser assegurado como a relação inconsciente e reconhecível de fazer a prática, de acordo com os autores sociais, que nesse caso são a alta diretoria e os gerentes, indivíduos que detêm o poder de gestão da organização e que têm habilidades e interesses em fazer as mudanças (Galleli \& Hourneaux, 2019). Essas práticas são possíveis de serem implementadas dependendo da necessidade da organização ou do mercado, sendo que essa relação reflete a motivação que a organização tem em implantar a sustentabilidade organizacional à gestão do negócio.

Segundo os autores Van Marrewijk e Werre (2003), a organização é que escolhe qual nível de interesse de sustentabilidade é o mais adequado, com vista aos objetivos e estratégias direcionadas para a empresa; esse padrão é o que vai diferenciar e direcionar os valores e os propósitos da organização. Os autores moldaram um modelo de hierarquia com os seis diferentes graus de interesse quanto à sustentabilidade, visando ao melhor desempenho organizacional.

Na Tabela 2 apresenta-se uma breve descrição de cada sistema de valores com relação às percepções do meio ambiente (condições de vida) que induzem o valor sistema da sustentabilidade, conduzindo, assim, ao nível da sustentabilidade organizacional.

\section{Tabela 2}

A relação dos sistemas de valores no nível da sustentabilidade organizacional

\begin{tabular}{|c|c|c|c|}
\hline Valor (cor) & Formas de expressão & Níveis & Interesse \\
\hline $\begin{array}{l}\text { Energia e } \\
\text { poder (ver- } \\
\text { melho) }\end{array}$ & $\begin{array}{l}\text { Unidades fortes para provar o } \\
\text { próprio poder. } \\
\text { Atuação enérgica e egocêntrica. } \\
\text { Rápido para agir, muitas vezes } \\
\text { impulsivo e descontrolado. } \\
\text { Liderança dominante. }\end{array}$ & $\begin{array}{l}1^{\circ} \text { nível: Pré-Susten- } \\
\text { tabilidade Organiza- } \\
\text { cional }\end{array}$ & $\begin{array}{l}\text { Não existência de aspiração à sus- } \\
\text { tentabilidade. } \\
\text { As ações são iniciadas por pressão } \\
\text { externa, como legislações e exigência } \\
\text { dos consumidores. } \\
\text { Necessidade de monitoramento } \\
\text { constante para o desenvolvimento } \\
\text { de ações de sustentabilidade. }\end{array}$ \\
\hline $\begin{array}{l}\text { Ordem } \\
\text { (azul) }\end{array}$ & $\begin{array}{l}\text { Um acordo é um acordo. } \\
\text { Clareza para todos, ordeira, } \\
\text { obediente à autoridade legítima. } \\
\text { Regras e regulamentos, lógica } \\
\text { do passo a passo. } \\
\text { A tarefa atribuída é o foco, não } \\
\text { a pessoa. }\end{array}$ & $\begin{array}{l}2^{\circ} \text { nível: Sustentabili- } \\
\text { dade Organizacional } \\
\text { em Conformidade } \\
\text { com a Legislação }\end{array}$ & $\begin{array}{l}\text { Existência da sustentabilidade limi- } \\
\text { tada à legislação exigida vigente. } \\
\text { As ações podem ser por imposição } \\
\text { de marketing, como comportamento } \\
\text { ambientalmente correto. } \\
\text { Responde à demanda das ações de } \\
\text { caráter sociais diversos, como ações } \\
\text { de caridade e voluntariado. }\end{array}$ \\
\hline
\end{tabular}




\begin{tabular}{|c|c|c|c|}
\hline Valor (cor) & Formas de expressão & Níveis & Interesse \\
\hline $\begin{array}{l}\text { Comunida- } \\
\text { de (Verde) }\end{array}$ & $\begin{array}{l}\text { Tolerância e aceitação de dife- } \\
\text { renças. } \\
\text { Agrupar, compartilhar e cuidar } \\
\text { de outros, consenso. } \\
\text { Usando as qualidades uns dos } \\
\text { outros para mútuo crescimento. } \\
\text { Faz juízos relativos à situação. }\end{array}$ & $\begin{array}{l}4^{\circ} \text { nível: Sustentabili- } \\
\text { dade Organizacional } \\
\text { Consciente }\end{array}$ & $\begin{array}{l}\text { Há existência de equilíbrio entre os } \\
\text { pilares da sustentabilidade econômi- } \\
\text { co, social e ambiental. } \\
\text { Ações que vão além da conformida- } \\
\text { de legal. } \\
\text { Visa ações voltadas ao capital hu- } \\
\text { mano, à responsabilidade. }\end{array}$ \\
\hline $\begin{array}{l}\text { Sinergia } \\
\text { (amarelo) }\end{array}$ & $\begin{array}{l}\text { Autodesenvolvimento e ambien- } \\
\text { te mentalmente preocupados. } \\
\text { Focado na capacidade de } \\
\text { aprender e aplicar conhecimen- } \\
\text { to. } \\
\text { Formulários organizacionais fle- } \\
\text { xíveis dependendo de situações. } \\
\text { Liderança forte sem dominar / } \\
\text { uso de poder. }\end{array}$ & $\begin{array}{l}5^{\circ} \text { nível: } \\
\text { Sustentabilidade } \\
\text { Organizacional Sinér- } \\
\text { gica }\end{array}$ & $\begin{array}{l}\text { Busca as funcionalidades que } \\
\text { valorizem a promoção das ações } \\
\text { que evidenciam os três pilares da } \\
\text { sustentabilidade. } \\
\text { A colaboração e participação é } \\
\text { dada por todos os stakeholders. } \\
\text { Há o desenvolvimento de índices } \\
\text { de desempenho organizacionais, } \\
\text { que valorizem e evidenciem os três } \\
\text { pilares da sustentabilidade. } \\
\text { Visa com maior ênfase ao pilar } \\
\text { social, com o desenvolvimento de } \\
\text { projetos voltados ao meio ambiente } \\
\text { e ao desenvolvimento organizacio- } \\
\text { nal. }\end{array}$ \\
\hline $\begin{array}{l}\text { Vida } \\
\text { holística } \\
\text { sistema } \\
\text { (Turquesa) }\end{array}$ & $\begin{array}{l}\text { Pensamento global. } \\
\text { Visão mais ampla do trabalho, } \\
\text { vida e natureza. } \\
\text { Cuidar dos recursos naturais e } \\
\text { humanos como uma entidade. } \\
\text { Mais desinteressada e altruísta } \\
\text { com foco na visão holística. }\end{array}$ & $\begin{array}{l}6^{\circ} \text { nível: Sustentabili- } \\
\text { dade Organizacional } \\
\text { Holística }\end{array}$ & $\begin{array}{l}\text { A integração dos pilares da susten- } \\
\text { tabilidade é embutida e incorpora- } \\
\text { da ao processo das estratégias de } \\
\text { gestão. } \\
\text { Visa contribuir para a qualidade de } \\
\text { toda a cadeia produtiva. } \\
\text { A responsabilidade e a ética estão a } \\
\text { cargo de todos na organização. }\end{array}$ \\
\hline
\end{tabular}

Nota. Adaptada de "Multiple levels of corporate sustainability," de M. Van Marrewijk, \& M. Werre, 2003, Journal of Business ethics, 44(2-3), p. 44.

A Tabela 2 apresenta a relação existente entre os Sistemas de Valores e os Níveis da Sustentabilidade Organizacional. O primeiro nível é o da Pré-Sustentabilidade Organizacional, cor Vermelha, o qual faz relação com a energia, muitas vezes, egocêntrica para provar o poder que os atores sociais possuem na organização; nesse nível não é comum o interesse pelo gerenciamento da sustentabilidade, no entanto os autores identificam alguns fatores em ações, como na legislação e nos canais de comunicação com os consumidores, iniciados nessa época, embora com um relacionamento ainda bastante rígido e pouco dinâmico.

No segundo nível está a Sustentabilidade Organizacional em Conformidade com a Legislação, com a cor Azul; tem-se a ordem como fator de valor, a gestão ocorre de maneira ordenada e satisfaz as exigências legais, como os regulamentos, com tarefas atribuídas ao foco; as pessoas estão em segundo plano, o nível de sustentabilidade organizacional tem um grau de interesse que se limita à legislação vigente, com ações voltadas mais ao marketing verde da empresa, ou seja, "somos ambientalmente corretos." No terceiro nível Sustentabilidade Organizacional orientada pelo Lucro -, o laranja é a cor que marca o valor do sucesso; atribui-se a questão das melhorias de maneira pragmática que, baseadas em 
soluções objetivas e simples, visa-se ao lucro da organização; o pilar econômico prevalece diante do social e do ambiental.

O quarto nível é a Sustentabilidade Organizacional Consciente, no qual prevalece a ênfase na comunidade com a cor verde, com tolerância e aceitação das diferenças, como crenças, cultura, cor de pele, dentre outros, que a sociedade compartilha e agrega como valores da comunidade em termos sociais; nesse nível de sustentabilidade já se molda um olhar mais atento para a questão da diversidade, com o equilíbrio dos pilares social e ambiental, começando a haver ações mais concretas para o capital humano nas organizações como fator de responsabilidade social.

Já no quinto nível a Sustentabilidade Organizacional é Sinérgica, cujo valor é a sinergia e a cor amarela, denominada pelo autodesenvolvimento, foco na capacidade cooperativa dos agentes, que têm capacidade de aprender, aplicar e replicar o conhecimento. Por meio da maior flexibilidade na organização, os agentes sociais buscam a funcionalidade das promoções de ações que evidenciem os três pilares da sustentabilidade, com a colaboração de todos os stakeholders por um bem comum: a sustentabilidade em si. Iniciam-se os índices de desempenho organizacional que visam valorizar indivíduos, contudo ainda há maior ênfase no pilar social, com projetos voltados ao meio ambiente para o desenvolvimento organizacional.

O último nível é a Sustentabilidade Organizacional Holística, com o sistema de valor na vida holística e a cor a turquesa; esse valor é voltado ao pensamento global, uma visão mais ampla do trabalho e não fragmentada, com maior cuidado com o meio ambiente $e$ com os recursos naturais, agregando a consciência ecológica e visando ao bem social. A lucratividade, no entanto, é necessária e economicamente correta, objetivando contribuir com toda a cadeia produtiva, sendo a sustentabilidade uma responsabilidade de todos na organização.

Após expostas algumas das contribuições a respeito dos modelos de gestão de pessoas e os níveis de sustentabilidade organizacional, passa-se para os procedimentos metodológicos.

\section{PROCEDIMENTOS METODOLÓGICOS}

O método qualitativo foi o mais adequado com o objetivo deste estudo, que é compreender de que forma acontece o alinhamento dos modelos estratégico e sustentável da gestão de pessoas e os níveis de sustentabilidade organizacional de duas indústrias de papel e celulose, sendo esse método útil para o atingimento dos objetivos, que eram: a) verificar qual modelo de gestão de pessoas as indústrias utilizam, na visão dos atores sociais; 
b) identificar quais sistemas de valores são os mais evidenciados nas empresas; e c) apontar as principais características dos níveis de sustentabilidade encontrados nas empresas.

Segundo Minayo (2011), a pesquisa qualitativa busca por dados subjetivos, valores, crenças, opiniões, hábitos e fenomenologia para contextualizar a coleta de dados que ora abrange a pesquisa de campo por meio da observação e participação direta ou indireta, ora por meio de entrevistas como objeto de pesquisa.

Esses objetivos puderam ser atingidos por meio da pesquisa exploratória e foram analisados por meio do estudo do conteúdo, por intermédio do qual se buscam os pressupostos interpretativos, sendo adotada a ontologia da Interação sujeito-objeto. Segundo Crotty (1998), a discussão entre pesquisadores nas ciências sociais aplicada à postura que vai embasar a metodologia deve estar dentro da metodologia escolhida dentre as que melhor respondem à questão ou hipótese da pesquisa. No que se refere à epistemologia utilizada, foi a construtivista, o paradigma foi o interpretativista, o qual, segundo Sacool (2009), sugere que os pressupostos de interação sujeito e pesquisa ocorrem na construção da realidade do sujeito com o objetivo central da pesquisa.

O método de pesquisa foi o estudo de casos múltiplos, e as técnicas de coleta e análise de dados foram entrevista e observação assistemática com análise do conteúdo. Quanto à população que foi investigada, foi definida mediante o problema ou a pergunta de pesquisa. Cooper e Schindler (2016) afirmam que a população a ser estudada são os elementos, as unidades a serem mensuradas em grupo ou individualmente. Quanto às empresas de análise, delimita-se que o estudo de caso foi realizado em duas empresas de produção de papel e celulose brasileiras; essas organizações possuem no portfólio individual ações voltadas à sustentabilidade de maneira concreta, com ações que se direcionam aos objetivos propostos para o estudo. Salienta-se que o direcionamento estratégico e os objetivos foram condizentes com o desempenho sustentável organizacional, além do ramo da indústria de papel e celulose estar incluído na legislação do Sistema de Gestão Ambiental (SGA).

Assim, a escolha do campo de estudo foi o ramo da indústria de papel e celulose no Brasil, o qual vem tratando com maior ênfase o termo sustentabilidade para a transformação do setor e o avanço da inovação tecnológica, além da revolução nos modelos de gestão.

Pode-se mencionar a inclusão das indústrias brasileiras no índice internacional Environmental Paper Company Index (EPCI), do World Wildlife Fund (WWF) (2017) Fundo Mundial para a Vida Selvagem (livre tradução) -, "entre as principais indústrias, estrategicamente importantes em termos de sustentabilidade ao redor do globo"; o índice aponta o desempenho ambiental das empresas desde 2009, acompanhando-o e divulgando-o de forma pública a cada dois anos (Oliari et al., 2018, p. 2).

As empresas foco do estudo foram Amazônia cia de Papel e Celulose, e Mata Atlântica cia de Papel e Celulose, cabendo ressaltar que os nomes são fictícios para resguardar 
a identidade das empresas. Ambas estão estabelecidas no Brasil há mais de 60 anos e aceitaram fazer parte da pesquisa.

Os sujeitos da pesquisa de cada empresa foram os diretores e colaboradores estratégicos e táticos das áreas de Gestão Estratégica, Gestão de Sustentabilidade e Gestão de Pessoas, colaboradores que foram escolhidos com base no seu conhecimento e atuação dentro das empresas. Também foi feita uma visita técnica na indústria que será denominada Amazônia; presenciou-se o processo desde o recebimento da matéria-prima até o produto acabado, assim como os refeitórios dos colaboradores e os escritórios, portaria e expedição. Na segunda empresa, Mata Atlântica cia, não houve visita técnica, a observação ocorreu no setor administrativo, portaria e durante o deslocamento entre portaria e setor administrativo.

Os meios primários foram obtidos por meio de entrevistas com roteiros semiestruturados com funcionários estratégicos e táticos dos setores de gestão estratégica, gestão de pessoas e gestão da sustentabilidade; as entrevistas ocorreram entre os meses de dezembro de 2018 e abril de 2019 nas unidades estudadas, com duração em média de 45 minutos, via telefone e presencialmente. Segundo Yin (2015), os protocolos de investigação são essenciais para a confiabilidade e a ética da pesquisa científica, os quais foram desenvolvidos com o auxílio de revisão da literatura.

O modelo semiestruturado de três roteiros de entrevistas foi construído com base na literatura para cada área: Gestão Estratégica, Gestão de Pessoas e Gestão de sustentabilidade; com o auxílio do referencial teórico, cada roteiro foi direcionado em três momentos da coleta de dados, melhor exemplificado nos apêndices em Oliari (2019).

Os meios secundários foram obtidos por meio das técnicas que envolveram levantamento bibliográfico, análise documental e observação assistemática in loco, bem como em documentos disponibilizados de forma pública e privada. Pela triangulação entre as informações teóricas, a caracterização exposta permite afirmar que a pesquisa realizada foi desenvolvida por uma estratégia de estudo de caso (Yin, 2005).

Contudo, foi necessário que a pesquisa seguisse pelo rigor metodológico, com fidedignidade e confiabilidade dos dados coletados e analisados, apresentando os construtos de validade para a pesquisa qualitativa, como o uso de protocolo, fonte de dados secundários oficiais e de domínio público.

Para a análise dos dados utilizaram-se as seguintes técnicas: análise de conteúdo, com a construção do Mapa de Associação das ideias, o qual será denominado Mapa de Associação do Conteúdo, uma vez que se teve acesso aos dados coletados nas entrevistas; observações diretas e indiretas; e documentos das organizações coletados de forma on-line. Segundo Spink (2010), são associadas na construção dos mapas de associação de ideias os dados encontrados nas entrevistas, que servem para indicar os principais achados na coleta 
de dados para a posterior análise do conteúdo, o que possibilitou o aproveitamento de todas das fontes de dados ainda sem serem lapidadas, conforme indicado por Bardin (1977).

Visando reduzir os dados obtidos para melhor organização, realizou-se a análise cruzada dos casos; segundo Yin (2015), esse tipo de análise em múltiplos casos pode ser em uma empresa, em diferentes departamentos, ou entre empresa e departamentos, e tem o pressuposto de contatar os diferentes dados contrastantes entre os casos estudados que apresentam os pontos divergentes e convergentes e realizar a triangulação de fonte de dados, foram utilizados o protocolo e o Termo de Consentimento Livre e Esclarecido (TCLE). A Tabela 3 descreve o perfil dos entrevistados por áreas e os códigos utilizados para identificá-los.

\section{Tabela 3}

Técnicas e Instrumentos de Coleta de Dados

\begin{tabular}{|c|c|c|}
\hline Caso & Entrevistas e Observações & Documentos \\
\hline \multirow{13}{*}{ 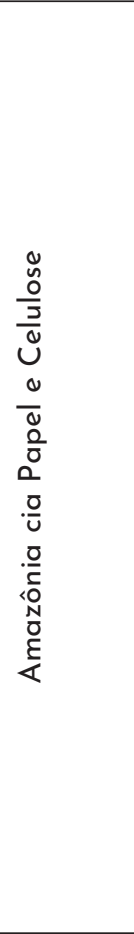 } & 1) AMA DIR 1 - Telefone. & Documentos públicos: \\
\hline & 2) AMA GP 1 - Telefone. & * Prêmios e Reconhecimentos AMA (site da empresa). \\
\hline & 3) AMA GP 2 - Presencial. & Certificações e Selos: \\
\hline & 4) AMA GP/RS 3 - Presencial. & * FSC ${ }^{\circledR}$ (FOREST STEWARDSHIP COUNCIL); \\
\hline & $\begin{array}{l}\text { 5) AMA SUST } 2 \text { - Presencial - } \\
\text { (contato imediato). }\end{array}$ & * ISO 14001 (VERSÃO 2015); \\
\hline & & *ISO 9001 (VERSÃO 2015). \\
\hline & & * Certificação ISEG; \\
\hline & & * Selo SESI ODS (2017). \\
\hline & & Programas: \\
\hline & & * PROJETO AMA Por Você - entrevista. \\
\hline & & Ações: \\
\hline & & $\begin{array}{l}\text { *Prêmio - (2001) - site da empresa; } \\
\text { "Revista, livros e artigos (site da empresa). }\end{array}$ \\
\hline & Visita às instalações Unidade 1 & $\begin{array}{l}\text { Documentos internos: } \\
\text { Informativo AMA \& Você (documento impresso); } \\
\text { Projeto Sustentabilidade na prática (documento impresso); } \\
\text { Lista de funcionários. }\end{array}$ \\
\hline \multirow{4}{*}{ 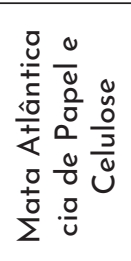 } & \multirow{4}{*}{$\begin{array}{l}\text { 1) MATAI DIR } 1 \text { - Presencial. } \\
\text { 2) MATAI GP } 1 \text { - Presencial. } \\
\text { 3) MATA2 GP } 2 \text { - Presencial, } \\
\text { (contato imediato). } \\
\text { 4) MATA SUST - Presencial. }\end{array}$} & $\begin{array}{l}\text { Documentos públicos: website da empresa } \\
\left.{ }^{*} \text { Forest Stewardship Council (FSC }{ }^{\circledR}\right) \text {. }\end{array}$ \\
\hline & & Documentos internos: \\
\hline & & Organograma; \\
\hline & & Pesquisas de satisfação. \\
\hline
\end{tabular}

A Tabela 3 identifica, com base nos dados coletados, as fontes primárias da coleta de dados, sendo utilizada a entrevista individual semiestruturada; na pesquisa documental foram utilizados resumos e notas, registros das observações assistemáticas no diário de campo, documentos privados que foram disponibilizados pelas empresas e documentos de livre acesso 
no website das empresas, como políticas, missão, visão, objetivos, programas, premiações e certificações, assim como outros relatórios que foram autorizados e encaminhados pelos participantes do estudo e colocados ordenadamente no protocolo de coleta de dados das empresas.

A seguir, apresenta-se a análise dos dados coletados a partir dos eixos dispostos na metodologia escolhida para responder à indagação e alcançar os objetivos propostos para a pesquisa.

\section{ANÁLISE E DISCUSSÃO DOS RESULTADOS}

Por meio da coleta de dados, que buscou registrar os dados coletados nas entrevistas conforme questionário e observação assistemática, com o registro no diário de campo, foi possível verificar os dados que serão analisados e discutidos na sequência para responder aos objetivos desta pesquisa. As duas empresas estudadas são do ramo de papel e celulose, as quais passam a ser sucintamente descritas. A Amazônia Cia de Papel e Celulose iniciou suas atividades em 1956; possui mais de 750 funcionários no grupo, no entanto, na unidade estudada, eram 471 no período da pesquisa. Possui capacidade total de produção de 140 mil toneladas de produto acabado, com representação nacional e internacional, contribuindo, assim, para a produção de embalagens, livros, materiais promocionais e demais produtos na área gráfica, seus produtos são utilizados em diversos setores, como indústria calçadista, de medicamentos, de alimentação e bebidas, entre outros (dados do site da empresa, 2019).

A Mata Atlântica Cia de Papel e Celulose foi fundada no ano de 1962; a unidade estudada faz parte do Grupo Mata Atlântica, o qual tem mais de 530 funcionários; o grupo é composto por duas hidroelétricas, uma fazenda de produção agrícola e a unidade fabril, com 386 funcionários em 29 de abril de 2019, segundo dados fornecidos pelo setor de gestão de pessoas. Com produção de $105 \mathrm{mil}$ toneladas de papel/ano, o principal produto produzido é a linha de papéis, a qual é composta por uma variedade de produtos offset, apergaminhados, monolúcido, kraft branco, inclusive aperfeiçoados para impressão a laser e formulário contínuo.

A Tabela 4 apresenta as articulações que auxiliaram na resposta ao primeiro objetivo específico: a) verificar qual modelo de gestão de pessoas as indústrias utilizam, na visão dos atores sociais. 


\section{Tabela 4}

Principais articulações do primeiro objetivo específico

\begin{tabular}{|c|c|c|}
\hline Objetivo & Amazônia & Mata Atlântica \\
\hline \multirow{9}{*}{ 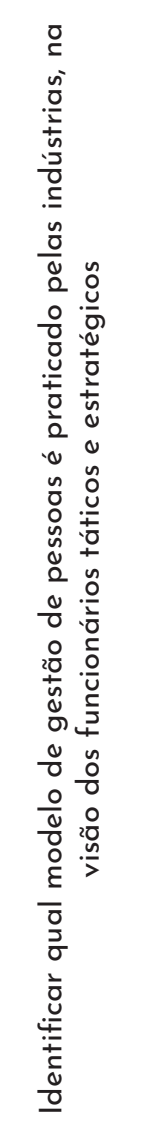 } & $\begin{array}{l}\text { Estratégico, conforme AMA GP l: "no planeja- } \\
\text { mento estratégico é que nos próximos dois ou } \\
\text { três anos..." }\end{array}$ & $\begin{array}{l}\text { Sustentável, conforme STA DIR: "Temos como } \\
\text { valor responsabilidade socioambiental, então } \\
\text { a parte social e meio ambiente e segurança do } \\
\text { trabalho..." }\end{array}$ \\
\hline & $\begin{array}{l}\text { Cultura organizacional e posicionamento do } \\
\text { mercado competitivo voltado ao planejamento } \\
\text { estratégico, segundo AMA GP l: "então hoje o } \\
\text { posicionamento nosso é pensando no planeja- } \\
\text { mento estratégico". }\end{array}$ & $\begin{array}{l}\text { Cultura organizacional e posicionamento de } \\
\text { mercado global, voltado para a missão, visão, } \\
\text { valores, conforme STA DIR, direcionamento } \\
\text { de negócios ... missão, visão, valores, ajustes } \\
\text { executivos. }\end{array}$ \\
\hline & $\begin{array}{l}\text { Segundo AMA DIR 2: "a gente está buscando } \\
\text { principalmente na parte de sustentabilidade, } \\
\text { revisão desse planejamento estratégico..." }\end{array}$ & $\begin{array}{l}\text {.. compartilhando com um níve } \\
\text { até a gente criar, então a criaç } \\
\text { toda a empresa, e a gente acre } \\
\text { em nossa missão, visão e valore }\end{array}$ \\
\hline & $\begin{array}{l}\text { Os pilares d } \\
\text { formalizado }\end{array}$ & $\begin{array}{l}\text { Os pilares da suster } \\
\text { zados na missão, vi }\end{array}$ \\
\hline & $\begin{array}{l}\text { Formação direcionada dos líderes estratégicos e } \\
\text { dos principais indivíduos envolvidos no planeja- } \\
\text { mento dos pilares da sustentabilidade. }\end{array}$ & $\begin{array}{l}\text { Consultores terceirizados na formalização das } \\
\text { estratégias direcionando as pessoas envolvidas } \\
\text { no acompanhamento da implementação dos } \\
\text { pilares da sustentabilidade. }\end{array}$ \\
\hline & $\begin{array}{l}\text { Ações impactam nas estratégias da organiza- } \\
\text { ção e nas estratégias de sustentabilidade. }\end{array}$ & $\begin{array}{l}\text { Trabalho de acompanhamento dos valores } \\
\text { já enraizados na cultura e formalizados nas } \\
\text { práticas sociais. }\end{array}$ \\
\hline & $\begin{array}{l}\text { Fatores estratégicos abrangentes, porém com } \\
\text { menos padronização. }\end{array}$ & $\begin{array}{l}\text { Fatores estratégicos abrangentes e padroniza- } \\
\text { dos. }\end{array}$ \\
\hline & \multicolumn{2}{|c|}{$\begin{array}{l}\text { Profissionais ligados à gestão de pessoas são mobilizados para dar suporte ao ciclo de transfor- } \\
\text { mação. }\end{array}$} \\
\hline & \multicolumn{2}{|c|}{ A sustentabilidade é praticada em todos os níveis da empresa como parte da rotina. } \\
\hline
\end{tabular}

A Tabela 4 apresenta a caracterização geral das duas empresas analisadas, com o objetivo de melhor visualizar o modelo de gestão de pessoas praticadas pelas organizações. A Empresa Amazônia segue o modelo de gestão de pessoas baseada nas estratégias. Esse modelo busca atingir o desempenho organizacional por meio das estratégias planejadas e deliberadas pela alta administração, com as ações dos agentes promotores das práticas sociais com as políticas e práticas formuladas no planejamento estratégico. A empresa Mata Atlântica, por sua vez, segue o modelo de gestão sustentável de pessoas; as ações já estão formalizadas nos valores da empresa para a implementação da sustentabilidade.

Respondendo ao segundo objetivo específico da pesquisa, qual seja, b) identificar quais os sistemas de valores são mais evidenciados nas empresas, apresenta-se a Tabela 5. 


\section{Tabela 5}

Os Sistemas de Valores Organizacionais

\begin{tabular}{|c|c|c|c|}
\hline Valor (cor) & Formas de expressão & Amazônia & Mata Atlântica \\
\hline \multirow{4}{*}{$\begin{array}{l}\text { Energia e } \\
\text { poder (ver- } \\
\text { melho) }\end{array}$} & Unidades fortes para provar o próprio poder. & - & - \\
\hline & Atuação enérgica e egocêntrica. & - & - \\
\hline & Rápido para agir, muitas vezes impulsivo e descontrolado. & - & - \\
\hline & Liderança dominante. & $\mathrm{b}$ & $b$ \\
\hline \multirow{4}{*}{$\begin{array}{l}\text { Ordem } \\
\text { (azul) }\end{array}$} & Um acordo é um acordo. & - & - \\
\hline & Clareza para todos, ordeira, obediente à autoridade legítima. & - & - \\
\hline & Regras e regulamentos, lógica do passo a passo. & $\mathrm{b}$ & $\mathrm{p}$ \\
\hline & A tarefa atribuída é o foco, não a pessoa. & - & - \\
\hline \multirow{4}{*}{$\begin{array}{l}\text { Sucesso } \\
\text { (laranja) }\end{array}$} & Sucesso é orientado para resultados, melhoria. & - & - \\
\hline & Meios servem o fim, pragmático. & - & - \\
\hline & Linhas informais e pragmáticas de comunicação. & - & - \\
\hline & Desejo de competir e se tornar melhor. & $\mathrm{b}$ & $\mathrm{p}$ \\
\hline \multirow{4}{*}{$\begin{array}{l}\text { Comunidade } \\
\text { (Verde) }\end{array}$} & Tolerância e aceitação de diferenças. & J & $p$ \\
\hline & Agrupar, compartilhar e cuidar de outros, consenso. & $\mathrm{b}$ & $\mathrm{p}$ \\
\hline & Usando as qualidades uns dos outros para mútuo crescimento. & J & - \\
\hline & Faz juízos relativos à situação na mão. & - & - \\
\hline \multirow{4}{*}{$\begin{array}{l}\text { Sinergia } \\
\text { (amarelo) }\end{array}$} & Autodesenvolvimento e ambiente mentalmente preocupados. & $\mathrm{b}$ & b \\
\hline & Focado na capacidade de aprender e aplicar conhecimento. & $\mathrm{b}$ & J \\
\hline & Formulários organizacionais flexíveis dependendo de situações. & J & b \\
\hline & Liderança forte sem dominar / uso do poder legitimo. & $\mathrm{b}$ & $p$ \\
\hline \multirow{4}{*}{$\begin{array}{l}\text { Sistema } \\
\text { Vida Holísti- } \\
\text { ca (Turque- } \\
\text { sa) }\end{array}$} & Pensamento global. & $\mathrm{b}$ & $\mathrm{p}$ \\
\hline & Visão mais ampla de trabalho, vida e natureza. & $\mathrm{b}$ & $p$ \\
\hline & Cuidar dos recursos naturais e humanos como uma entidade. & $\mathrm{b}$ & $\mathrm{b}$ \\
\hline & Mais desinteressada e altruísta com foco na visão holística. & $\mathrm{p}$ & $\mathrm{b}$ \\
\hline
\end{tabular}

A Tabela 5 identifica, com base na coleta de dados, e expressa os sistemas de valores nos quais as organizações apresentaram evidências; as empresas apresentaram grande relevância nos três últimos valores, sendo eles: comunidade na cor verde, com ênfase maior nas expressões; tolerância e aceitação de diferenças; e agrupar, compartilhar e cuidar de outros, consenso. Sinergia com a cor amarela; autodesenvolvimento e ambiente mentalmente preocupados, focado na capacidade de aprender e aplicar conhecimento, formulários organizacionais flexíveis dependendo de situações, liderança forte sem dominar / uso do poder legítimo. E sistema de vida holística com a cor turquesa, com pensamento global, visão mais ampla de trabalho, vida e natureza, cuidar dos recursos naturais e humanos como uma entidade, mais desinteressada e altruísta com foco na visão holística.

Isso não significa, no entanto, que os três primeiros valores não tenham relevância; foi verificada a existência de pontos, como na questão dos valores de Energia e poder, na 
cor vermelha, a forma de expressão foi liderança dominante; no valor da ordem, na cor azul, foi regras e regulamentos e lógica do passo a passo; assim como no valor de sucesso, cor laranja, a forma de expressão foi desejo de competir e se tornar melhor.

Assim, na Tabela 6 visa-se responder ao último objetivo: c) apontar as principais características dos níveis de sustentabilidade encontrados nas empresas.

\section{Tabela 6}

Níveis de Sustentabilidade Organizacionais

\begin{tabular}{|c|c|c|c|}
\hline Níveis & Interesse & Amazônia & $\begin{array}{c}\text { Mata } \\
\text { Atlântica }\end{array}$ \\
\hline \multirow{3}{*}{$\begin{array}{l}1^{\circ} \text { nível } \\
\text { Pré-sustentabilidade } \\
\text { organizacional }\end{array}$} & Não existência de aspiração à sustentabilidade. & & - \\
\hline & $\begin{array}{l}\text { As ações são iniciadas por pressão externa, como legis- } \\
\text { lações e exigência dos consumidores. }\end{array}$ & 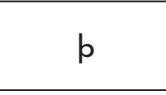 & $J$ \\
\hline & $\begin{array}{l}\text { Necessidade de monitoramento constante para o de- } \\
\text { senvolvimento de ações de sustentabilidade. }\end{array}$ & b & $J$ \\
\hline \multirow{3}{*}{$\begin{array}{l}2^{\circ} \text { nível } \\
\text { Sustentabilidade Orga- } \\
\text { nizacional em Conformi- } \\
\text { dade com a Legislação }\end{array}$} & $\begin{array}{l}\text { Existência da sustentabilidade limitada à legislação } \\
\text { exigida vigente. }\end{array}$ & & \\
\hline & $\begin{array}{l}\text { As ações podem ser por imposição de marketing, como } \\
\text { comportamento ambientalmente correto. }\end{array}$ & - & - \\
\hline & $\begin{array}{l}\text { Responde à demanda das ações de caráter social diver- } \\
\text { sas, como ações de caridade e voluntariado. }\end{array}$ & - & - \\
\hline \multirow{2}{*}{$\begin{array}{l}3^{\circ} \text { nível Sustentabilidade } \\
\text { Organizacional } \\
\text { orientada pelo Lucro }\end{array}$} & $\begin{array}{l}\text { As ações nos processos de tomada de decisão, visando } \\
\text { à lucratividade e ao desenvolvimento econômico da } \\
\text { organização. }\end{array}$ & b & $b$ \\
\hline & $\begin{array}{l}\text { Ações de marketing voltadas para a promoção da mar- } \\
\text { ca visando ao lucro organizacional. }\end{array}$ & & \\
\hline \multirow{3}{*}{$\begin{array}{l}4^{\circ} \text { nível Sustentabilidade } \\
\text { Organizacional } \\
\text { Consciente }\end{array}$} & $\begin{array}{l}\text { Há existência de equilíbrio entre os pilares da sustenta- } \\
\text { bilidade econômico, social e ambiental. }\end{array}$ & $\mathrm{b}$ & $\mathrm{b}$ \\
\hline & $\begin{array}{l}\text { São praticadas ações que vão além da conformidade } \\
\text { legal. }\end{array}$ & $\mathrm{b}$ & $J$ \\
\hline & $\begin{array}{l}\text { Visa ações voltadas ao capital humano, à responsabili- } \\
\text { dade. }\end{array}$ & $\mathrm{p}$ & $\mathrm{b}$ \\
\hline \multirow{4}{*}{$\begin{array}{l}5^{\circ} \text { nível Sustentabilidade } \\
\text { Organizacional } \\
\text { Sinérgica }\end{array}$} & $\begin{array}{l}\text { Busca as funcionalidades que valorizem a promoção } \\
\text { das ações que evidenciam os três pilares da sustentabi- } \\
\text { lidade. }\end{array}$ & $J$ & $\mathrm{~b}$ \\
\hline & $\begin{array}{l}\text { A colaboração e participação é dada por todos os } \\
\text { stakeholders. }\end{array}$ & - & $\mathrm{b}$ \\
\hline & $\begin{array}{l}\text { Há o desenvolvimento de índices de desempenho orga- } \\
\text { nizacionais que valorizem e evidenciem os três pilares } \\
\text { da sustentabilidade. }\end{array}$ & $\mathrm{p}$ & $J$ \\
\hline & $\begin{array}{l}\text { Visa com maior ênfase ao pilar social, com o desenvol- } \\
\text { vimento de projetos voltados ao meio ambiente e ao } \\
\text { desenvolvimento organizacional. }\end{array}$ & $J$ & $b$ \\
\hline \multirow{3}{*}{$\begin{array}{l}6^{\circ} \text { nível } \\
\text { Sustentabilidade Orga- } \\
\text { nizacional Holística }\end{array}$} & $\begin{array}{l}\text { A integração dos pilares da sustentabilidade é embuti- } \\
\text { da e integrada ao processo das estratégias de gestão. }\end{array}$ & - & $\mathrm{b}$ \\
\hline & $\begin{array}{l}\text { Visa contribuir para a qualidade de toda a cadeia } \\
\text { produtiva. }\end{array}$ & 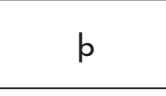 & $\mathrm{b}$ \\
\hline & $\begin{array}{l}\text { A responsabilidade e a ética são responsabilidades de } \\
\text { todos na organização. }\end{array}$ & $\mathrm{p}$ & $\mathrm{b}$ \\
\hline
\end{tabular}


A Tabela 6 visou analisar o interesse das empresas quanto à questão da sustentabilidade organizacional; com relação aos níveis da sustentabilidade, as empresas apresentaram interesse em todos eles; nos níveis iniciais, isso ocorreu por uma questão mais de legislação e integração ao meio no qual estão inseridas.

A empresa Amazônia não incluiu no portfólio estratégico da organização o termo sustentabilidade, mantendo-o no modelo de gestão estratégico e no $5^{\circ}$ Nível - Sustentabilidade Organizacional Sinérgica -, no qual predomina o valor da sinergia, com a cor amarela, denominada pelo autodesenvolvimento, foco na capacidade cooperativa dos agentes, que têm capacidade de aprender, aplicar e replicar o conhecimento. Com maior flexibilidade na organização os agentes sociais, buscam a funcionalidade das promoções de ações que evidenciem os três pilares da sustentabilidade, com a colaboração de todos os stakeholders para um bem comum, a sustentabilidade.

Segundo Gonçalves et al. (2017), ao identificar as políticas e práticas da gestão de pessoas que são relatadas nas entrevistas, em documentos, ou expostas no website das empresas, é possível identificar também os níveis de sustentabilidade organizacional das empresas. Esse nível integra cada pilar da sustentabilidade nos processos de gestão, visando manter a qualidade de vida, a manutenção e continuação da vida atual e futura, por meio da manutenção econômica da empresa e das ações dos seus atores sociais, observando com maior atenção a sustentabilidade e a responsabilidade social, assim com o equilíbrio entre os pilares econômico, social e ambiental, com práticas de gestão de pessoas que integram a sustentabilidade além das exigidas pela legislação, podendo citar as ações voluntárias feitas pelos funcionários.

No entanto, apesar de os índices de desempenho organizacional visarem à valorização dos indivíduos e objetivarem os três pilares da sustentabilidade, ainda há maior ênfase no pilar social, com projetos voltados ao meio ambiente para o desenvolvimento organizacional. Não se encontra no sexto nível ainda, porque não incluiu o termo sustentabilidade formalmente no planejamento estratégico, na missão, visão e objetivos da empresa.

A empresa Mata Atlântica atingiu o sexto nível de Sustentabilidade Organizacional Holística com o sistema de valor na vida holística, com a cor turquesa. Esse valor é voltado ao pensamento global, uma visão mais ampla do trabalho e não fragmentada, com maior cuidado com o meio ambiente, com os recursos naturais, agregando a consciência ecológica e visando ao bem social. No entanto, a lucratividade é necessária e economicamente correta, visando contribuir com toda a cadeia produtiva; sendo assim, a sustentabilidade é responsabilidade de todos na organização.

O nível de sustentabilidade organizacional sinérgico busca valorização das pessoas e ações que evidenciam os três pilares da sustentabilidade por meio das práticas e da 
participação de todos os stakeholders, assim como a ênfase no pilar social com projetos voltados ao meio ambiente, à responsabilidade social e à ética.

Cabe ressaltar, todavia, que tanto a Amazônia quanto a Mata Atlântica integram algum item relevante nos níveis anteriores ao de sua posição, uma vez que isso faz parte do interesse comum, ou exigências legais. Assim, atingindo os objetivos específicos, foi possível alcançar o objetivo geral da pesquisa, a saber, compreender de que forma acontece o alinhamento dos modelos estratégico e sustentável da gestão de pessoas e os níveis de sustentabilidade organizacional de duas indústrias de papel e celulose.

Foi possível compreender que os níveis de sustentabilidade de cada empresa revelam a íntima relação entre os níveis e os modelos de gestão de pessoas seguido pelas empresas. Os dados demonstraram que o alto nível de sustentabilidade organizacional apresentado pelas empresas é influenciado pelo modelo estratégico de pessoas sustentável entre as duas temáticas, uma vez que a relação das políticas e práticas de gestão de pessoas é um ícone de extrema importância na implantação e implementação da gestão da sustentabilidade organizacional, corroborando as pressuposições do referencial teórico.

\section{CONCLUSÃO}

Os níveis de sustentabilidade organizacional, segundo Van Marrewijk e Werre (2003), dizem respeito ao interesse da organização quanto às abordagens da sua sustentabilidade, de acordo com as abordagens estratégicas da organização; essa concepção, no entanto, muitas vezes não condiz com a realidade organizacional, pois muitas organizações não estão preocupadas com os níveis de maturidade como colocado na academia, seguindo unicamente os instintos da necessidade de mercado. Cabe, então, mover de um nível inicial da pré-sustentabilidade para um nível mais avançado, como o holístico. No entanto, níveis de sustentabilidade organizacional são um processo desafiador, uma vez que se caracterizam ao longo do tempo pela colaboração e planejamento correto da alta diretoria.

No entanto, salienta-se que para que a sustentabilidade organizacional tenha êxito em seus três pilares, é essencial que as políticas e práticas de gestão de pessoas sejam conduzidas pelos praticantes de maneira concreta e espontânea; nesse sentido, o alinhamento estratégico sustentável é de extrema importância para as organizações, pois será nas ações concretas da gestão de pessoas que os caminhos escolhidos para atingir a sustentabilidade vão se concretizar por meio dos atores sociais como principais agentes de mudanças nas transformações organizacionais.

Cabe ressaltar que os dados encontrados por meio das entrevistas e das observações em cada empresa revelam que os níveis de sustentabilidade apresentam relação entre os níveis e a gestão de pessoas dado o nível de maturação (estratégias, políticas e práticas) das 
empresas em termos de sustentabilidade organizacional, em que a articulação dos modelos de gestão de pessoas é parte integradora desse processo, com práticas e políticas voltadas à sustentabilidade, corroborando as pressuposições identificadas na literatura.

Como contribuição para a abordagem dessa temática, este estudo propôsse a compreender a relação entre os modelos de gestão de pessoas, o que pode mover as organizações entre os níveis de sustentabilidade organizacional. Os resultados desta pesquisa permitem demonstrar que os casos estudados envolvem os modelos de gestão de pessoas seguidos pelas empresas, que estão diretamente ligados ao nível de sustentabilidade e que, por meio das práticas dos atores sociais, desenvolvem a integração dos pilares da sustentabilidade nos processos das estratégias de gestão organizacional e a inserção da qualidade em toda a cadeia produtiva para a redução de riscos para o ecossistema, sendo um exemplo apresentado pelas empresas a contratação de funcionários capacitados em gestão ambiental e sustentabilidade para dar suporte à cadeia de produção.

Uma vez que os modelos de gestão de pessoas estratégica e sustentável seguidos pelas organizações são modelos que incluem a sustentabilidade nas estratégias das organizacionais em todos os departamentos, contribui para estarem no nível mais elevado da sustentabilidade organizacional o nível holístico (o carácter, a ética e a responsabilidade) apresentado na configuração das organizações, como descrevem Van Marrewijk e Werre (2003), em que o pensamento e as ações das organizações são global e amplamente divulgadas a todos na organização, como as estratégias que visam ao meio ambiente inseridas nas estratégias organizacionais e as ações praticadas pelos atores sociais voltadas à sustentabilidade organizacional.

\section{REFERÊNCIAS}

Albuquerque, L. G. D., Leite, N. P., \& Silva, L. M. T. D. (2009). Estimulando o debate sobre a gestão estratégica de pessoas. Editora Atlas.

Andrade, L. B. L., De Laat, E. F., \& Stefano, S. R. (2018). Qualidade de vida no trabalho e comprometimento com a carreira de diretores de escolas públicas. Revista Eletrônica de Ciência Administrativa, 17(1), 54-83.

Araújo, L. C. G. (2006). Gestão de pessoas: Estratégias e integração organizacional. Editora Atlas.

Badawy, M. K. (1988). What we've learned: Managing human resources. Research-Technology Management, 31(5), 19-35.

Bardin, L. (1977). Análise de conteúdo (4a ed.). Edições 70. http://b-ok.cc/ book/2660061/117106 
Beck, D., \& Cowan, C. (1996). Spiral dynamics: Mastering values, leadership and change. Blackwell Publishers.

Borim-De-Souza, R., \& Segatto, A. P. (2015). Apresentando a teoria da gestão comparativa. Revista de Administração de Empresa, 55(3), 359-367.

Brundtland, G. H. (1987). Our common future: The World Commission on Environment and Development. Oxford University Press.

Cobb, Willson, T. M., J. E., Cowan, D. J., Wiethe, R. W., Correa, I. D., Prakash, S. R., Beck, K. D., Moore, L. B., Kliewer, S. A., \& Lehmann, J. M. (1996). The Structure - Activity relationship between peroxisome proliferator-activated receptor $\gamma$ agonism and the antihyperglycemic activity of thiazolidinediones. Journal of medicinal chemistry, 39(3), 665-668.

Cooper, D. R., \& Schindler, P. S. (2016). Métodos de Pesquisa em Administração (12a ed.). McGraw Hill Brasil.

Crotty, M. (1998). The foundations of social research: Meaning and perspective in the research process. Sage. http://b-ok.xyz/book/2923832/d6fcd5

Drucker, P. (2012). The practice of management. Routledge.

Elkington, J. (2001). Cannibals with forks: The triple bottom line of 21st century business. Capstone Publishing Limited.

Elkington, J., \& Zeitz, J. (2014). The breakthrough challenge: 10 ways to connect today's profits with tomorrow's bottom line. John Wiley \& Sons.

Fischer, A. L. (1998). A constituição do modelo competitivo de gestão de pessoas no Brasil: um estudo sobre as empresas consideradas exemplares (Doctoral dissertation, Universidade de São Paulo).

Fischer, A. L. (2002). Um resgate conceitual e histórico dos modelos de gestão de pessoas. In M. T. L. Fleury, As pessoas na organização (pp. 11-34). Gente. http://www.diferencialmg. com.br/site/images/artigos/Gesto\%20estratgica\%20de\%20pessoas\%20artigo.pdf

França, A. C. L. (2015). Práticas de recursos humanos. Atlas. 
Galpin, T., Whitttington, J. L., \& Bell, G. (2015). Is your sustainability strategy sustainable? Creating a culture of sustainability. Corporate Governance, 15(1), 1-17. https://www. researchgate.net/publication/276237230_Is_your_sustainability_ strategy_sustainable_ Creating_a_culture_of_sustainability

Galleli, B., \& Hourneaux, F., Jr. (2019). Human competences for sustainable strategic management: Evidence from Brazil. Benchmarking: An International Journal, 26(2).

Gonçalves, M. F., Stefano, S. R., \& Baccaro, T. A. (2017). Sustentabilidade organizacional e suas relações com a gestão estratégica de pessoas: Um estudo de caso em uma cooperativa agroindustrial. Revista de Administração da Unimep, 15(3), 51-73.

Henry, L. A., Buyl, T., \& Jansen, R. J. (2019). Leading corporate sustainability: The role of top management team composition for triple bottom line performance. Business Strategy and the Environment, 28(1), 173-184.

Igarashi, M. H.,Ramos-Dias, J. C., Libardi, M. C., Zillo, C. M., , \& Senger, M. H. (2010). Qualidade de vida em cem alunos do curso de Medicina de Sorocaba-PUC/SP. Rev Bras Educ Med, 34(1), 116-23.

Marras, J. P. (2017). Gestão estratégica de pessoas. Saraiva.

Marras, J. P. \& Tose, M. (2013). Avaliação de desempenho humano. Elsevier Brasil.

Minayo, M. C. S. (2011). Capítulo 3, Trabalho de campo: Contexto de observação, interação e descoberta. Pesquisa social: Teoria, método e criatividade, p. 61.

Munck, L., Bansi, A. C., \& Galleli, B. (2016). Sustentabilidade em contexto organizacional: Uma análise comparativa de modelos que propõem trajetórias para sua gestão. Revista de Ciências da Administração, 18(44), 91-110.

Oliari, T. B. P. (2019). Modelo de gestão de pessoas alinhado aos pilares da sustentabilidade organizacional: Um estudo nas indústrias de papel e celulose. Dissertação de Mestrado, Universidade Estadual do Centro-Oeste, Guarapuava.

Oliari, T. B. P., Zaias, L. J. L., \& Merigo, A. T. L. (2018). Sustentabilidade e a dimensão ambiental: Estabelecendo um ranking a partir do Índice Environmental Paper Company In$\operatorname{dex}(\mathrm{EPCl})$. Anais do Encontro Internacional sobre Gestão Ambiental e Meio Ambiente, São Paulo, 20, 1-17.

Oliveira, D. C. D. (2008). Análise de conteúdo temático-categorial: Uma proposta de sistematização. Revista enfermagem UERJ, 16(4), 569-576. 
Organização das Nações Unidas no Brasil. (2015). Portal oficial. https://nacoesunidas.org/ acao/meio-ambiente.

Orlickas, E. (2012). Modelos de gestão: Das teorias da administração. Ed. Ibpex.

Parente, T., \& Fischer, A. (2015). Recursos humanos e sustentabilidade: Uma revisão bibliométrica. Anais do Encontro Internacional sobre Gestão Ambiental e Meio Ambiente, São Paulo, 14, 1-15.

Pires, F. M., \& Fischer, A. L. (2014). Integração entre gestão de pessoas e estratégia de sustentabilidade: $O$ caso Natura. Revista de Gestão Social e Ambiental, 8(1), 54.

Sacool, L. A. Z. (2009). Um retorno ao básico: Compreendendo os paradigmas de pesquisa e sua aplicação na pesquisa em administração. Revista de Administração da UFSM, $2(2), 250-269$.

Savitz, A., \& Weber, K. (2013). Talent, transformation, and the triple bottom line: How companies can leverage human resources to achieve sustainable growth. John Wiley \& Sons.

Spink, M. J. (2010). Linguagem e produção de sentidos no cotidiano. In M. J. Spink, Cap. III - As múltiplas faces da pesquisa sobre produção de sentidos no cotidiano (pp. 38-59). Centro Edelstein de Pesquisas Sociais.

Sroufe, R., Liebowitz, J., Sivasubramaniam, N., \& Donahue, J. F. (2010). Are you a leader or a laggard? HR's role in creating a sustainability culture. People \& Strategy, 33(1), 34-42.

Trompenaars, F., \& Coebergh, P. H. (2014). 100+ management models: How to understand and apply the world's most powerful business tools. Infinite Ideas.

Uddin, N., \& Hossain, F. (2015). Evolution of modern management through Taylorism: An adjustment of scientific management comprising behavioral science. Procedia Computer Science, 62, 578-584.

Ulrich, D. (1998). A new mandate for human resources. Harvard business review, 76, 124-135.

Van Marrewijk, M., \& Werre, M. (2003). Multiple levels of corporate sustainability. Journal of Business ethics, 44(2-3), 107-119.

Veiga, J. E. D. (2010). Indicadores de sustentabilidade. Estudos avançados, 24(68), 39-52. 
Vosburgh, R. M. (2007). The evolution of HR: Developing HR as an internal consulting organization. People and Strategy.

World Wildlife Fund. (2017). http:// www.worldwildlife.org

Yin, R. K. (2015). Qualitative research from start to finish. Guilford Publications.

\section{Como citar este artigo:}

\section{ABNT}

OLIARI, Terezinha Bernadete Pinto; STEFANO, Silvio Roberto; ANDRADE, Sandra Mara de. Alinhamento entre modelos de gestão de pessoas e os níveis de sustentabilidade organizacional. RACE, Revista de Administração, Contabilidade e Economia, v. 19, n. 3, p. 593-618, set./dez. 2020. Disponível em: http://editora.unoesc.edu.br/index.php/race. Acesso em: dia/mês/ano.

\section{APA}

Oliari, T. B. P., Stefano, S. R., \& Andrade, S. M. (2020). Alinhamento entre modelos de gestão de pessoas e os níveis de sustentabilidade organizacional. RACE, Revista de Administração, Contabilidade e Economia, 19(3), 593-618. http://editora.unoesc.edu.br/index. php/race 